\title{
Improvement of Soil Respiration Parameterization in a Dynamic Global Vegetation Model and Its Impact on the Simulation of Terrestrial Carbon Fluxes
}

\author{
DOnGMin Kim, MyOng-In LEE, AND EunKyo SEO \\ School of Urban and Environmental Engineering, Ulsan National Institute of Science \\ and Technology, Ulsan, South Korea
}

(Manuscript received 12 January 2018, in final form 3 October 2018)

\begin{abstract}
The $Q_{10}$ value represents the soil respiration sensitivity to temperature often used for the parameterization of the soil decomposition process has been assumed to be a constant in conventional numerical models, whereas it exhibits significant spatial and temporal variation in the observations. This study develops a new parameterization method for determining $Q_{10}$ by considering the soil respiration dependence on soil temperature and moisture obtained by multiple regression for each vegetation type. This study further investigates the impacts of the new parameterization on the global terrestrial carbon flux. Our results show that a nonuniform spatial distribution of $Q_{10}$ tends to better represent the dependence of the soil respiration process on heterogeneous surface vegetation type compared with the control simulation using a uniform $Q_{10}$. Moreover, it tends to improve the simulation of the relationship between soil respiration and soil temperature and moisture, particularly over cold and dry regions. The modification has an impact on the soil respiration and carbon decomposition process, which changes gross primary production (GPP) through controlling nutrient assimilation from soil to vegetation. It leads to a realistic spatial distribution of GPP, particularly over high latitudes where the original model has a significant underestimation bias. Improvement in the spatial distribution of GPP leads to a substantial reduction of global mean GPP bias compared with the in situ observation-based reference data. The results highlight that the enhanced sensitivity of soil respiration to the subsurface soil temperature and moisture introduced by the nonuniform spatial distribution of $Q_{10}$ has contributed to improving the simulation of the terrestrial carbon fluxes and the global carbon cycle.
\end{abstract}

\section{Introduction}

Vegetated land surface affects climate (Foley et al. 1998; Sellers et al. 1986) and is affected by climate significantly (Bonan 2008), forming complex interactions and feedback loops critical to climate change (Friedlingstein et al. 2006; Gregory et al. 2009). The land surface components of Earth system models (ESMs) have evolved from only representing biophysical processes (i.e., hydrology and energy cycling) to including biogeochemical processes, such as dynamic vegetation change and carbon and nutrient cycles driven by ecosystems (Oleson et al. 2013; Sitch et al. 2003; Wang et al. 2010). The carbon balance of terrestrial ecosystems is the result of the balance between carbon uptake and loss by plants and soil respiration $R_{S}$ (Beer et al. 2010; Malhi et al. 1999; Le Quéré et al. 2009; Luyssaert et al. 2007; Trumbore 2006). Lateral carbon fluxes by erosion and

Corresponding author: Myong-In Lee, milee@unist.ac.kr transport by aquatic continuum are also known to be significant in closing the global carbon budget (Regnier et al. 2013). Which terrestrial ecosystems act dominantly as sinks or sources has been a subject of considerable interest in studies of future climate change. Precise evaluations for each sink and source component and their responses to environmental factors are essential for reliable projection of future climate change by ESMs.

Future climate change projection by various ESMs driven by identical anthropogenic emissions is diverse and highly uncertain in the prediction of atmospheric $\mathrm{CO}_{2}$ concentration (Friedlingstein et al. 2006, 2014; Hoffman et al. 2014). Many previous studies (Friedlingstein et al. 2006; Hoffman et al. 2014; Anav et al. 2013; Arora et al. 2013; Friedlingstein et al. 2014) suggested that the large spread of $\mathrm{CO}_{2}$ concentration among the ESM simulations should be attributed to the difference in carbon cycle over land rather than over ocean. In particular, one of the main causes seems to be related to our poor knowledge of carbon exchange by soil, leading to 
significant diversity among the model simulations (ToddBrown et al. 2013).

Microbial decomposition of soil organic matter produces a major carbon flux from the subsurface biosphere. Previous studies investigated the response of $R_{s}$ under global warming, and most of them projected the warming would accelerate the release of $\mathrm{CO}_{2}$ from soil in future (Cox et al. 2000; Dufresne et al. 2002; Friedlingstein et al. 2003; Suseela et al. 2012). However, the amplitude of soil decomposition process has not been quantified through direct field measurements in the global domain. Because of a lack of in situ data, it is derived indirectly such as from subsurface soil temperature, soil moisture, soil type, and other factors (Koizumi et al. 2010; Zhou et al. 2009; Xu and Qi 2001; Qi et al.2002), which contain large uncertainties (Suseela et al. 2012). Luo et al. (2016) suggested that the optimal calibration of the parameters is needed based on observations in current ESMs. The reduction of uncertainties in the soil biogeochemical process remains a challenge for the ESM modeling community.

Soil respiration is considered a significant source of $\mathrm{CO}_{2}$ from terrestrial ecosystems. Recent studies suggest that $\mathrm{CO}_{2}$ emission change by soil should be largely driven by surface temperature change (Bond-Lamberty and Thomson 2010; Hursh et al. 2017). At global, regional, and local scales, temperature and moisture in the subsurface soil are considered the most important abiotic parameters determining $R_{s}$ (Kutsch et al. 2009). Empirical response functions based on heterogeneous field measurements are commonly used to derive annual estimates of $R_{s}$ (Tang and Baldocchi 2005).

The sensitivity of $R_{s}$ to temperature, the so-called $Q_{10}$ value, is required for parameterizing the soil decomposition process. Whether this value is a global constant or variable in space is still under debate and the conclusions from the previous studies are diverse, which reflect our limited understanding to the soil respiration process. For example, Mahecha et al. (2010) suggested that the $Q_{10}$ value is independent of mean annual temperature and the type of biomes. Karhu et al. (2014) also mentioned that the $Q_{10}$ is approximately a global constant of about 1.4, which is mostly supported by observed values obtained in the high-latitude regions in the Northern Hemisphere $(\mathrm{NH})$ in their study. Other studies, however, suggested that $Q_{10}$ may vary in space (Zhou et al. 2009; Xu and Qi 2001; Qi et al. 2002). Belay-Tedla et al. (2009) suggested that the global warming-induced changes in plant growth and vegetation types can influence the quality and quantity of substrates considerably, which in turn regulates the responses of soil respiratory carbon release to rising temperature. All the abiotic and biotic factors such as soil temperature (Lloyd and Taylor 1994; Kirschbaum 1995;
Luo et al. 2001), moisture (Davidson et al. 1998; Reichstein et al. 2002; Hui and Luo 2004), and soil organic matter (Taylor et al. 1989; Liski et al. 1999; Wan and Luo 2003) are heterogeneous, showing substantial spatial variation globally. Accordingly, estimated $Q_{10}$ from measured soil respiration possibly varies at various geographic locations (Xu and Qi 2001).

Based on the aforementioned studies, Zhou et al. (2009) developed an inverse model to retrieve the global pattern of heterogeneous $Q_{10}$ values by assimilating soil organic carbon data with a process-based biogeochemical model. They suggested that spatial distribution of $Q_{10}$ values changes according to vegetation type, with an increasing tendency as latitude increases. The impact on the estimation of carbon release due to $Q_{10}$ variation in space is a significant change of approximately $25 \%-40 \%$ compared with the use of a constant $Q_{10}$ value in Zhou et al. (2009). This result suggests that the determination of $Q_{10}$ value is important for the simulation of carbon-climate feedback and future climate change. A few land surface models recently attempted to specify different $Q_{10}$ values for the soil decomposition rate depending on the vegetation type (e.g., Brovkin et al. 2012; Schaphoff et al. 2018), emphasizing the importance of $Q_{10}$ variation in space. However, most advanced ESMs that participated in phase 5 of the Coupled Model Intercomparison Project (CMIP5) still use a globally constant $Q_{10}$ value in the dynamic global vegetation models (Anav et al. 2013; Todd-Brown et al. 2013). In this case, the sensitivity of subsurface carbon flux under global warming condition would not be reflected adequately in the model simulation.

Motivated by the above, this study developed a new parameterization method for determining $Q_{10}$ by considering the dependence of soil respiration on soil temperature, moisture, and the vegetation type, the relationship of which was obtained from multiple regression of the reference soil respiration data with those two predictors for each vegetation type. The Community Land Model, version 4 (CLM4), has the parameterization of the interactive carbon and nitrogen $(\mathrm{C}-\mathrm{N})$ cycle for the dynamic vegetation model, which was used to derive realistic spatial distributions of $Q_{10}$. Moreover, the realistic soil carbon decomposition processes affect not only $R_{s}$ but also primary production by improving nitrogen assimilation from soil to vegetation. This study further investigates the impacts of the new parameterization on the global carbon cycle.

Section 2 describes the observation and modeling data used in this study and the modeling method used to obtain the distribution of $Q_{10}$. Section 3 provides the results from the offline dynamic vegetation model tests with prescribed atmospheric states. This study examines particularly on the direct impacts of the modified $Q_{10}$ parameterization on soil respiration and consequent 
changes in carbon fluxes by terrestrial vegetation. A summary and further discussion are provided in section 4 .

\section{Data, methods, and experiments}

\section{a. Data}

FLUXNET is a global network of micrometeorological tower sites. It provides the global distribution of carbon and water fluxes and its temporal variation in the vegetated land surface, which were derived from upscaling eddy covariance measurements at the flux tower using a statistical machine-learning algorithm. This study used the gross primary production (GPP) products from the FLUXNETMTE (Multi Tree Ensemble) data (hereafter simply FLUXNET; Jung et al. 2009) as reference for the model validation. The data provide monthly GPP over the global domain gridded at $0.5^{\circ} \times 0.5^{\circ}$ (latitude-longitude) horizontal resolution for 23 years (1983-2009).

For the model validation, this study also used the GPP and net primary production (NPP) derived from the Moderate Resolution Imaging Spectroradiometer (MODIS) satellite measurements. The basis for deriving plant productivity from satellites is based on the plant physiological assumption that the NPP is proportional to the amount of solar energy absorbed by plants over a growing season (Monteith 1972). The MODIS GPP is a cumulative composite of daily values in 8-day interval derived by multiplying the radiation use efficiency parameter and the absorbed photosynthetically active radiation (APAR), in which the former is determined by the Biome Properties Lookup Table (BPLUT) data model depending on vegetation type, daily minimum temperature, and vapor pressure deficit (VPD) limitation, and the latter is estimated by the satellite-derived the fractional photosynthetically active radiation (FPAR) and the incident photosynthetically active radiation (PAR) produced by NASA Global Modeling and Assimilation Office (GMAO) atmospheric reanalysis data. The MODIS NPP is quantified by subtracting autotropic respiration $R_{a}$ from GPP. The term $R_{a}$ consists of maintenance $\left(R_{m}\right)$ and growth $\left(R_{g}\right)$ respiration extracted from the vegetationtype dependent BPLUT. Interested readers refer to the document for the MODIS GPP and NPP version 3.0 algorithm for more detail (available at https://lpdaac.usgs. gov/sites/default/files/public/product_documentation/ mod17_user_guide.pdf). The MODIS GPP and NPP data were gridded for the global domain at $0.5^{\circ} \times 0.5^{\circ}$ horizontal resolution for this study, which were originally from MODIS17A3 GPP and NPP products in HDF EOS (Hierarchical Data Format-Earth Observing System) format with a native resolution of $1 \mathrm{~km}$ (Running et al. 2004).

Although the MODIS GPP and NPP products may not be regarded as accurate as the in situ observations, previous studies indicated that they are consistent well with those from actual ground-based observations (Zhao et al. 2005; Kim et al. 2017). Comparing GPP between in situ observation-based FLUXNET and satellite-based MODIS, the two datasets show a minor difference for the overlapping period (2000-06). The global GPP of FLUXNET is $101.13 \mathrm{gC} \mathrm{m}^{-2}$ month $^{-1}$ and that of MODIS is $100.51 \mathrm{gC} \mathrm{m}^{-2}$ month $^{-1}$, which is comparable with a negligible difference of less than $1 \%$ compared to the total value.

Simulations of $R_{s}$ by CLM4 were verified using the gridded reanalysis dataset from Hashimoto et al. (2015), which has the data period of 1983-2005. The data were also used for the parameterization of soil respiration in this study, as will be described in detail in section 2c. Although directly observed soil respiration is available from version 3 of the Soil Respiration Database (SRDB; Bond-Lamberty and Thomson 2010), it has limited sampling for boreal cold regions (i.e., tundra and northern Siberian) as well as unpopulated regions in the tropics, covering a significant portion of the global biosphere. The data from Hashimoto et al. were derived using SRDB data and the empirical soil respiration model with specified climate conditions for surface air temperature and precipitation. The soil respiration model used in Hashimoto et al. (2015) was modified and updated from the original version of Raich et al. (2002). Global land use data in a synergetic land-cover product (SYNMAP) (Jung et al. 2006) using a Bayesian calibration scheme were used to determine the best parameter set for deriving the climatedriven model of soil respiration. The climate-forcing data were obtained from CRU, version 3.21, climate data (Jones and Harris 2013). These data were applied monthly at a spatial resolution of $0.5^{\circ}$ latitude $\times 0.5^{\circ}$ longitude. All the data were regridded onto $1.9^{\circ} \times 2.5^{\circ}$ latitude-longitude grids for comparison with the CLM4 simulation at this resolution.

\section{b. Soil respiration parameterization}

Most dynamic vegetation models implemented in current ESMs, including CLM4, adopt a simple type of empirical equation for $R_{s}$, which is proportional to the soil decomposition flux of carbon at the root zone. Soil decomposition process in CLM4 is tracking organic material from plant pools to the soil carbon pools. Soil carbon (C) pools consist of coarse woody debris (CWD), three litter pools, and four soil organic matter (SOM) pools, all for describing a complex decomposition cascade structure within soil. Each soil carbon pool is characterized by different 
turnover time and respired fraction, and also discretized in vertical to represent the vertical advection and diffusion processes. Soil mineral nitrogen $(\mathrm{N})$ experiences mineralization or immobilization between organic nitrogen $(\mathrm{N})$ pools analogously defined as in the paths for the $\mathrm{C}$ pools.

Based on Thornton and Rosenbloom (2005), the decomposition flux $D$ in CLM4 is calculated as

$$
D_{n}=\frac{C_{n} R_{\text {scalar }}}{\Delta t}\left(1.0-R_{n}-\mathrm{CN}_{n}\right)
$$

where the subscript $n$ is designated for the $n$th discretized carbon pool; $C_{n}$ is the carbon amount; $R_{\text {scalar }}$ is the rate scalar, which is a function of soil temperature and moisture; $\Delta t$ is the time step in the model; and $R_{n}$ is the soil respiration fraction for metabolic transfer to the downstream $(n+1)$ th pool, specified for each carbon pool with different constant values. $\mathrm{CN}_{n}$ represents the $\mathrm{C}: \mathrm{N}$ ratio of the $(n+1)$ th pool divided by the C:N ratio of the $n$th pool, and the C:N ratio is specified with different constant values for each carbon pool in CLM4. Therefore, the decomposition flux is state-dependent and dynamically changing by soil carbon amount and the environmental modifier $R_{\text {scalar }}$.

In (1), $R_{\text {scalar }}$ represents the effects of the physical environmental condition such as soil temperature $T_{\text {scalar }}$ and moisture $W_{\text {scalar }}$, further formulated as

$$
R_{\text {scalar }}=T_{\text {scalar }} W_{\text {scalar }},
$$

where $T_{\text {scalar }}$ is basically an exponential function of temperature from van't Hoff (1898). It is implemented in CLM4 as in the following equation:

$$
T_{\text {scalar }}=Q_{10}^{\left[\left(T_{j}-T_{\text {ref }}\right) / 10\right]},
$$

where $T_{j}$ is the temperature at the $j$ th soil level, and $T_{\text {ref }}$ is the reference temperature of $25^{\circ} \mathrm{C}$. CLM 4 considers temperature for the top five soil levels as representing the root zone ( $\sim 29-\mathrm{cm}$ depth); $\mathrm{Q}_{10}$ is specified as a constant value of 1.5 in the standard CLM4 model. The moisture scalar $W_{\text {scalar }}$ is based on the work of Andren and Paustian (1987), who describe the water potential for soil decomposition as

$$
W_{\text {scalar }}=\sum_{j=1}^{5} \frac{\log \left(\Psi_{\min } / \Psi_{j}\right)}{\log \left(\Psi_{\min } / \Psi_{\max }\right)},
$$

where $\Psi_{j}$ is the soil water potential at the level $j$ defined from the exponential of volumetric soil moisture $\left(\mathrm{m}^{3} \mathrm{~m}^{-3}\right), \Psi_{\max }$ is the maximum potential depending on soil type, and $\Psi_{\min }$ is the minimum value of $-10 \mathrm{MPa}$, regardless of soil type. The range of $W_{\text {scalar }}$ is $0-1$ by setting to 0 when the $\Psi_{j}$ is below $\Psi_{\min }$, and setting to 1 when $\Psi_{j}$ is above $\Psi_{\max }$.

\section{c. $Q_{10}$ parameterization}

For improving the $R_{s}$ parameterization in CLM4, this study considers a spatiotemporal change of $Q_{10}$ instead of a uniform constant in (3). Although the decomposition rate in CLM4 includes the dependency on soil temperature and moisture as in (2), $Q_{10}$ should be instantaneously varying at the given soil temperature and moisture, which is intended to provide more enhanced dependency between soil respiration and abiotic environmental condition. In our parameterization, this relationship also depends on plant function types.

For achieving this, we developed a multiple regression model for $Q_{10}$ based on Qi et al. (2002), which assumes that the rate of $R_{s}$ change depends entirely on soil temperature $T$ and soil moisture $M$. These two physical variables are well-known important factors for soil biological processes. The fractional instantaneous change of $R_{s}$ by soil temperature $q$ is defined as

$$
q(T, M)=\frac{1}{R_{s}} \frac{d R_{s}}{d T} .
$$

We define $Q_{10}$ as the relative change of $R_{s}$ at a temperature increase of $10^{\circ} \mathrm{C}$, which can be described in the following equations:

$$
\begin{aligned}
Q_{10}(T, M) & =\frac{R_{s}(T+5, X)}{R_{s}(T-5, X)} \text { and } \\
Q_{10} & =\exp \left[\int_{T-5}^{T+5} q(T, X) d T\right],
\end{aligned}
$$

where $X$ is any additional independent variable to predict $R_{s}$. In this case, only soil moisture is considered. From (7), $Q_{10}$ is a monotonic function of $q$, and the factor affecting $q$ also influences $Q_{10}$. Therefore, the change of $R_{s}$ is decomposed into the change by temperature and the change by moisture:

$$
\frac{d R_{s}}{d T}=\frac{\partial R_{s}(T, M)}{\partial M} \frac{d M}{d T}+\frac{\partial R_{s}(T, M)}{\partial T} .
$$

Inserting (8) into (5), the equation for $q$ is rewritten as

$$
q(T, M)=\frac{1}{R_{s}}\left[\frac{\partial R_{s}(T, M)}{\partial M} \frac{d M}{d T}+\frac{\partial R_{s}(T, M)}{\partial T}\right],
$$

where $d M / d T=-1 / 2.2=-0.455$, as suggested by $\mathrm{Xu}$ and Qi (2001). Although $d M / d T$ can vary in space and time, this study applied a constant value globally due to a lack of subsurface soil observations. Through a multiple regression analysis, the relationships between $R_{s}$ and $T$ and between $R_{s}$ and $M$ were obtained for each 


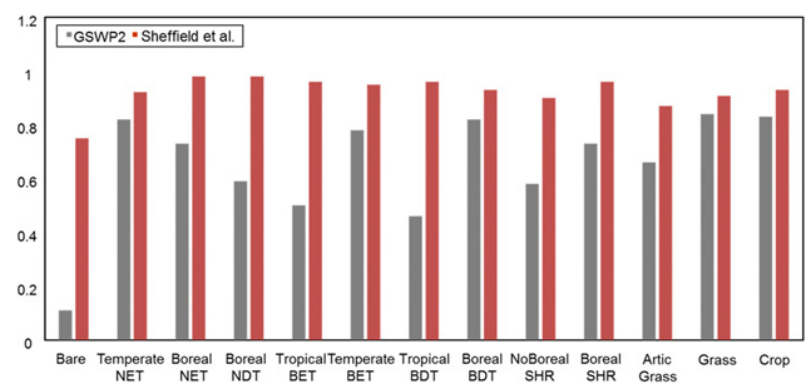

FIG. 1. Comparison of $r^{2}$ values in the multiple regression of soil respiration at each plant function type (PFT) with soil temperature and moisture obtained from (a) the ensemble average of 13 Global Soil Wetness Project (GSWP2) land surface model outputs for 10 years (1986-95) (gray bars) and (b) the offline CLM4 model output for 28 years (1983-2010) forced by Sheffield et al. (2006) data (red bars).

plant function type (PFT). CLM4 has 17 different PFTs. The most dominant PFT was used for the given grid cell when it was a mixture of multiple PFTs.

The parameterization also requires the dependence of soil respiration on subsurface temperature and moisture; these data are also not available from in situ observations. To obtain these variables, this study conducted the land surface reanalysis for recent 30 years (1981-2010), using the offline land surface model driven by observed meteorological forcing data archived by Sheffield et al. (2006). The 3-hourly forcing data by Sheffield et al. (2006) consist of the National Centers for Environmental Prediction (NCEP)-National Center for Atmospheric Research (NCAR) reanalysis data (Kalnay et al. 1996), which were corrected with independent observations. For precipitation, the daily Global Precipitation Climatology Project
(GPCP) (Huffman et al. 2001) data were processed into the 3-hourly data using the Tropical Rainfall Measuring Mission (TRMM) (Huffman et al. 2003) 3B42RT but constraining daily mean amount from GPCP. Surface temperature was constrained by the observation from the monthly Climatic Research Unit (CRU) 2.0 product (Mitchell et al. 2004). The observed radiation was also used from the monthly NASA Langley surface radiation budget (Stackhouse et al. 2004) data. Remaining meteorological conditions such as surface wind and humidity were from the NCEP-NCAR atmospheric reanalysis. Interested readers refer to Sheffield et al. (2006) for the detail. Using this 3-hourly forcing data, this study integrated the offline CLM4 model with 3-hourly time steps and at a $0.5^{\circ} \times 0.5^{\circ}$ spatial resolution for 28 years $(1983$ 2010).

As there might be large uncertainty in the simulation of subsurface soil temperature and moisture conditions, we examined the sensitivity to the observed meteorological forcing data used in the offline land surface model. Figure 1 shows the comparison of $r^{2}$ values for the two different multiple regression models for soil respiration reanalysis from Hashimoto et al., one with the soil temperature and moisture from the multimodel ensemble average of 13 Global Soil Wetness Project (GSWP2) land surface model outputs (Dirmeyer 2006), and the other with those from the offline CLM4 model outputs. In most vegetation types, the regression by soil temperature and moisture tends to exhibit high values close to 1 . The regression results are better than they are when the GSWP2 multimodel ensemble average was applied to the multiple regression. This difference is attributed mostly to a better quality of forcing data by Sheffield

TABLE 1. Multiple regression equations for soil respiration for each plant function type; $M$ indicates the volumetric soil moisture $\left(\mathrm{m}^{3} \mathrm{~m}^{-3}\right)$ and $T$ the soil temperature $\left({ }^{\circ} \mathrm{C}\right)$.

Plant functional type

Needleleaf evergreen temperate tree

Needleleaf evergreen boreal tree

Needleleaf deciduous boreal tree

Broadleaf evergreen tropical tree

Broadleaf evergreen temperate tree

Broadleaf deciduous tropical tree

Broadleaf deciduous temperate tree

Broadleaf deciduous boreal tree

Broadleaf evergreen shrub

Broadleaf deciduous temperate shrub

Broadleaf deciduous boreal shrub

C3 Arctic grass

C3 non-Arctic grass

$\mathrm{C} 4$ grass

C3_crop

C3_irrigated

Corn
Equations

$0.002055 M-0.00719+0.002055 T-0.00218$
$0.0025463 M-0.00786+0.002546 T-0.00217$
$0.0023144 M-0.0741+0.002413 T-0.00223$
$0.0011350 M+0.0736+0.001135 T+0.0148$
$0.000794 M+0.05993+0.00794 T+0.00270$
$0.002871 M-0.17061-0.00287 T+0.139927$
$0.000772 M+0.07462+0.00077 T+0.01115$
$0.002546 M-0.007862+0.00254 T-0.00217$
$0.002434 M+0.00511+0.00238 T-0.002731$
$0.001405 M+0.00547+0.00140 T+0.012359$
$0.002546 M+0.00786+0.00254 T-0.002177$
$0.002134 M+0.00628+0.00241 T-0.002813$
$0.001540 M+0.00461+0.00154 T+0.00428$
$0.001334 M+0.00773+0.00241 T-0.002254$
$0.001315 M+0.0010451+0.00034 T+0.0106$
$0.001315 M+0.0010451+0.00034 T+0.0106$
$0.000348 M+0.0010451+0.000348 T+0.0390$


a) $Q_{10}$ spatial distribution

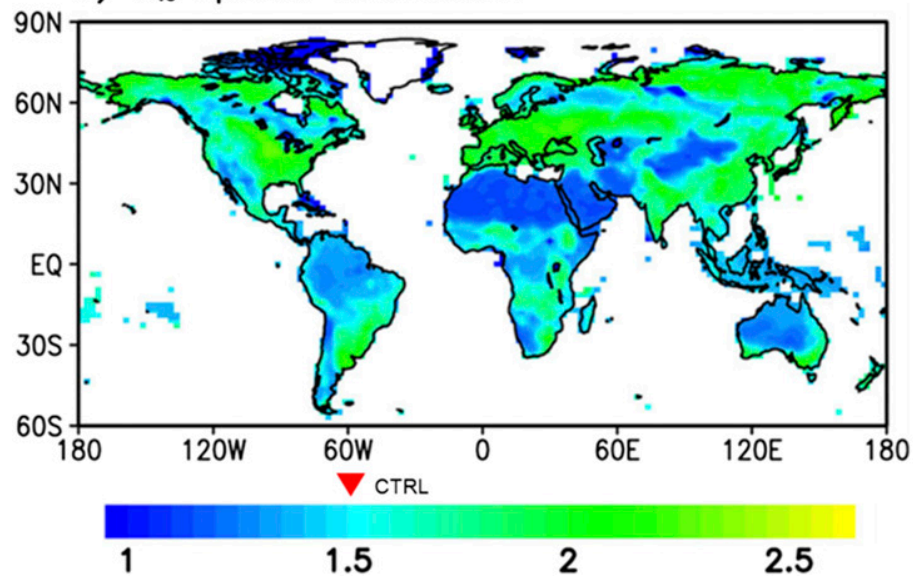

b) $Q_{10}$ zonal mean

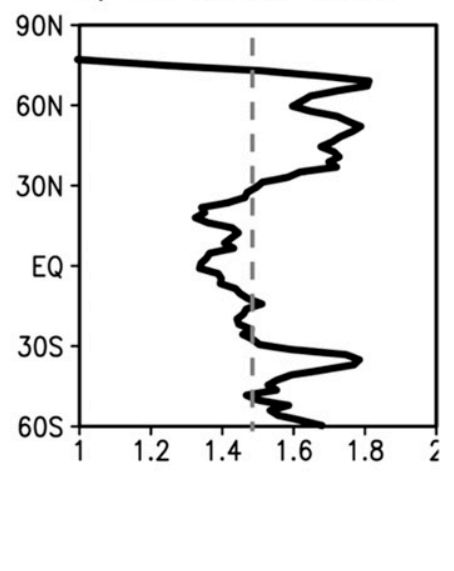

FIG. 2. (a) Spatial distribution of time-mean $Q_{10}$ simulated by the EXP experiment, and (b) the zonal mean of (a). Red triangle in (a) and gray dashed line in (b) both indicate a constant value of $Q_{10}=1.5$ used in the CTL experiment.

et al. (2006), such as the use of daily precipitation data instead of monthly values in GSWP2 and a longer training period from 1983 to 2010 than was used for GSWP2 data (1986-95). The $r^{2}$ value was found to be comparable when the period of forcing data was reduced. Based on this result, we used soil respiration data from Hashimoto et al. (2015), soil temperature and moisture data from the offline simulation using Sheffield data for 28 years to calculate multiple regression. Table 1 shows the multiple linear regression equations for soil respiration for each PFTs derived from this study.

The $Q_{10}$ multiple regression model developed in this study has an advantage over the treatment of constant value in the standard CLM4 model. First, the dependence of $R_{s}$ on soil moisture and temperature can be dependent on PFT. In addition, this approach is able to consider the nonlinear relationship between $R_{s}$ and the two major environmental variables of soil temperature and moisture, supported by recent observational studies (Davidson et al. 1998; Raich et al. 2002).

\section{d. Experiments}

Two sets of offline CLM4 simulations were conducted with identical meteorological forcing for 23 years (1983-2005), where the only difference was the specification of $Q_{10}$ in the control run (CTL) and the statedependent $Q_{10}$ for soil temperature and moisture in every time interval (EXP). The offline CLM4 simulations for GPP and soil respiration were also compared with those from the fully interactive Community Earth System Model with Biogeochemistry (CESM-BGC) simulation that shared the identical land surface model (i.e., CLM4). The dataset was obtained from Earth
System Grid-Center for Enabling Technologies (ESGCET at http://pcmdi9.1lnl.gov/). Figure 2 shows the time average of $Q_{10}$ values, where the geographical change is clear according to the dominant PFTs and climate conditions (Fig. 2a). Generally, the regions of lower canopy plants with cold soil temperatures exhibit significantly higher values than the default value of 1.5 in CTL (Fig. 2b). In contrast, the regions of lower $Q_{10}$ values are located at low latitudes in high temperatures, such as the Amazon and the Maritime Continent. This result suggests that soil respiration is more sensitive to the change of soil temperature in boreal vegetated regions in cold climates. In Table 2, the time-averaged $Q_{10}$ values obtained from the EXP run are given for seven major vegetation types.

\section{Results}

\section{a. Systematic biases of CLM4}

The time average of the offline simulation from the standard run (CTL) in Fig. 3 is generally similar to the fully interactive integration of the same model in terms of the spatial bias patterns for GPP and $R_{s}$, presumably inherited by the deficiencies in the parameterization of the dynamic vegetation model. The fully interactive model (CESMBGC) used an identical dynamic vegetation model with an

TABLE 2 . Time-averaged $Q_{10}$ values for seven vegetation types obtained from the EXP run.

\begin{tabular}{lccccccc}
\hline \hline Temperate & Boreal & Tropical & Shrub & $\begin{array}{c}\text { Boreal } \\
\text { shrub }\end{array}$ & Grass & Crop \\
\hline 1.446 & 1.762 & 1.374 & 1.266 & 1.918 & 1.842 & 2.041 \\
\hline
\end{tabular}


a) GPP (FLUXNET)

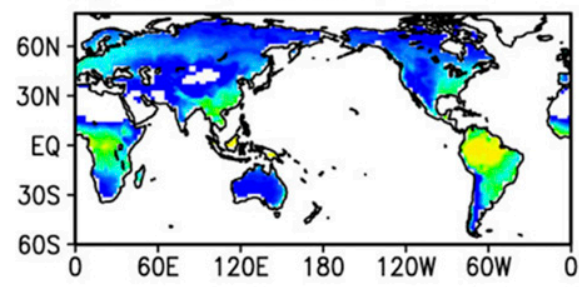

30

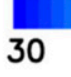

130

230

330

d) Rs (Hashimoto)

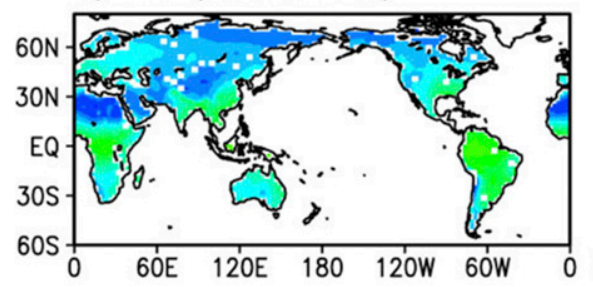

e) Rs (CESM-Hashimoto)

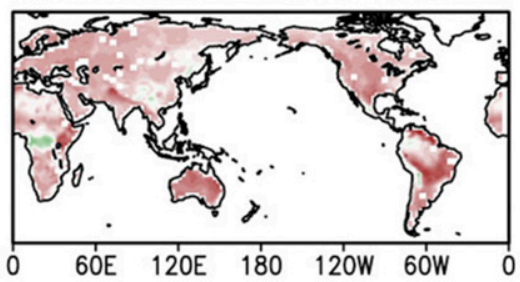

b) GPP (CESM-FLUXNET)

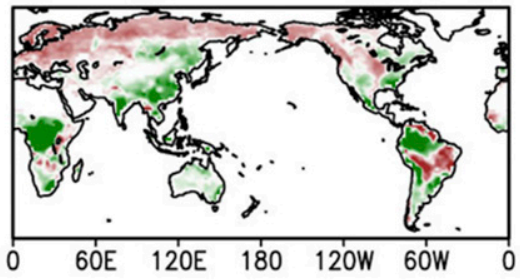

c) GPP ( CTL -FLUNET)

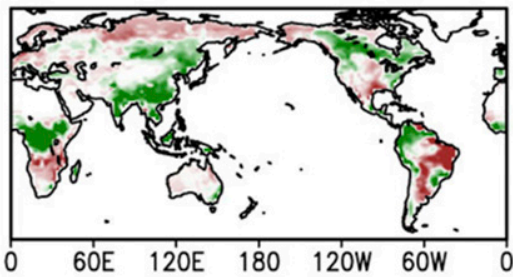

0

20

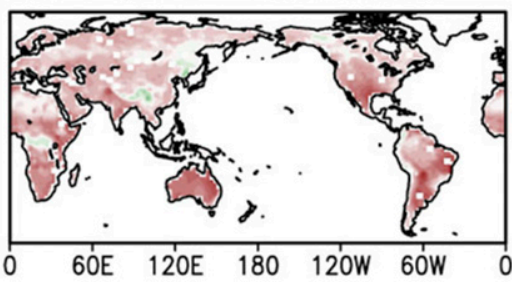

f) Rs ( CTL - Hashimoto)
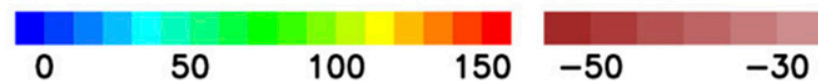

$-10$

10

30

50

FIG. 3. (top) Spatial distributions of (a) annual-mean GPP from the in situ observation-based FLUXNET data for 23 years (1983-2005), (b) the simulation bias in the interactive CESM run (CESM minus FLUXNET), and (c) the bias in the offline CTL run (CTL minus FLUXNET). (bottom) As in the top panel, but for (d) the annual-mean $R_{s}$ reanalysis from Hashimoto et al. and (e),(f) the simulation biases in CESM and CTL, respectively. The unit is $\mathrm{gC} \mathrm{m}^{-2}$ month $^{-1}$.

interactive $\mathrm{C}-\mathrm{N}$ cycle (Bonan et al. 2011) as in the case of CTL, as well as with the global constant $Q_{10}$. Both simulations (fully coupled and offline) tend to overestimate GPP over the tropics and underestimate it in high latitudes. The bias pattern of $R_{s}$ is also quite similar with no significant difference. The simulated climate in the fully interactive run should be different from the observed climate condition used to drive the offline CLM4 (not shown), because of the simulations errors in the fully coupled simulation. In spite of the difference in the climate condition, much resemblance in the terrestrial carbon-flux bias pattern between the two runs suggests that the biases in the carbon flux are overwhelmed by the deficiencies in the parameterization of the dynamic vegetation model, rather than by the differences in the climate condition.

We further compared the GPP simulation by the fully coupled CLM4 (CESM-BGC) with those by other stateof-the-art ESMs quantitatively, as well as with the FLUXNET reference data. Figure 4 shows the globaland area-averaged GPP values over several latitude belts from the multimodel ensemble (MME) average of 10 CMIP5 ESMs and the CESM-BGC run. Table 3 presents the list of 10 ESMs used in this study and their important features in the terrestrial biogeochemistry. The global GPP simulated by the MME is $119.28 \mathrm{gCm}^{-2}$ month $^{-1}$, which is overestimated by $18 \mathrm{gCm}^{-2}$ month $^{-1}$ from the FLUXNET reference data. Overall, MME shows realistic meridional variation with large values in the tropics and small values in high latitudes. As identified in previous studies, however, the ESMs tend to overestimate

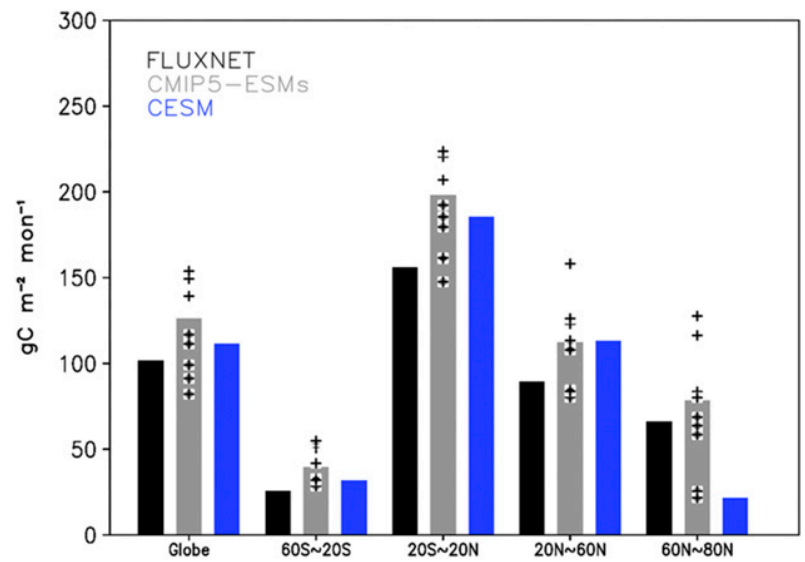

FIG. 4. Regional average of GPP from FLUXNET (black) for 23 years (1983-2005), the multimodel ensemble (MME) mean simulated by 10 CMIP5 ESMs (gray), and the single model run by CESM (blue). The plus signs in the gray bars indicate the values from individual models. 


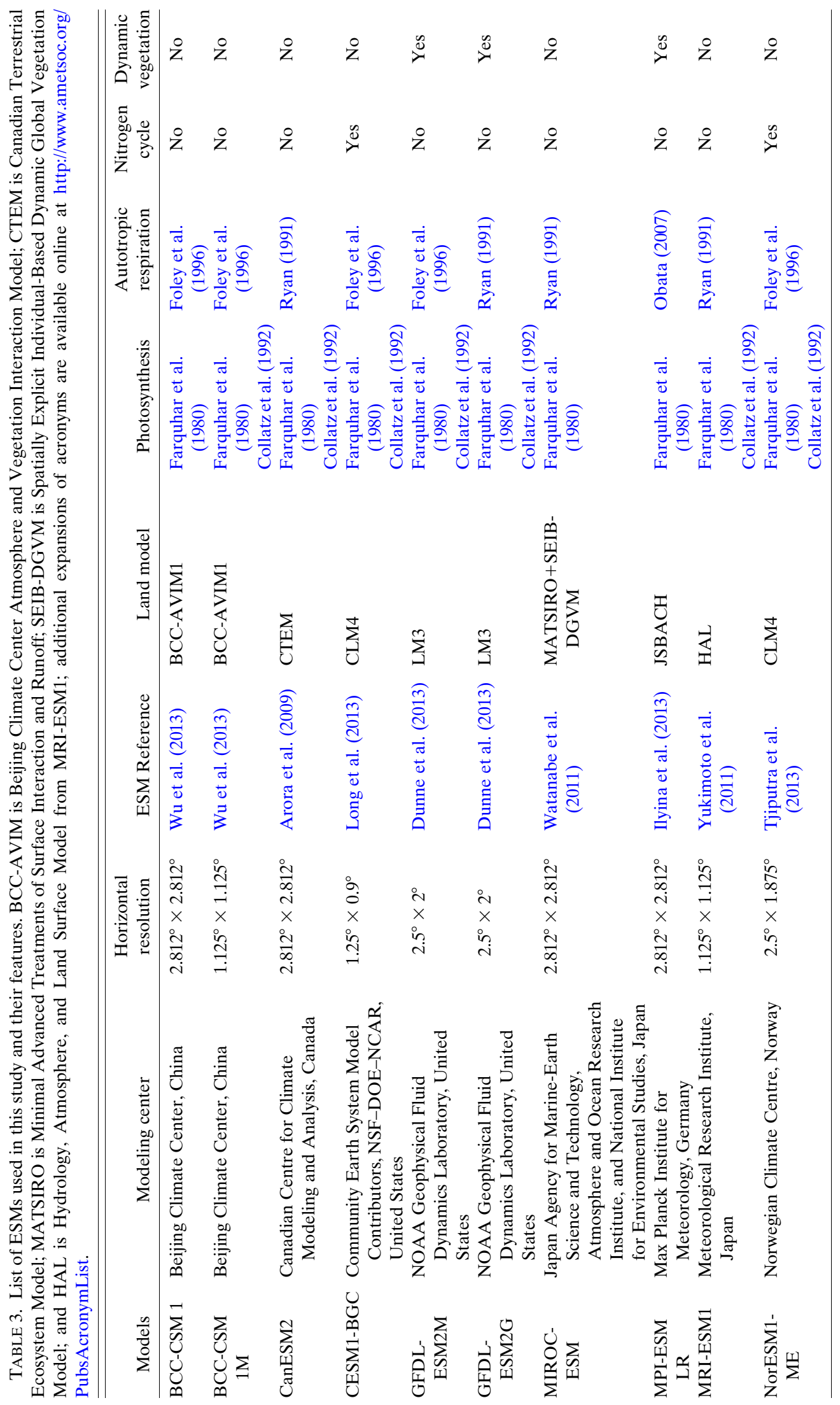


GPP significantly in the tropics (Shao et al. 2013; Anav et al. 2013). Global GPP simulated by CESM-BGC is lower than that by MME $\left(-11.53 \mathrm{gCm}^{-2}\right.$ month $\left.^{-1}\right)$. Including typical biases of overestimation of GPP over tropical belts $\left(20^{\circ} \mathrm{S}-20^{\circ} \mathrm{N}\right)$, CESM-BGC show tends to significantly underestimate GPP in the NH high latitudes $\left(>60^{\circ} \mathrm{N}\right)$. These systematic biases are a common problem in the $\mathrm{C}-\mathrm{N}$ coupled models based on CLM4 (Bonan et al. 2011; Thornton et al. 2009).

By sharing identical land surface model and terrestrial biogeochemistry, the bias patterns from the offline CTL run show much resemblance to that from the fully interactive case as shown in Fig. 3, and our analysis and experiments will be focused more on the offline model tests in the remaining of this study. In the following section, the impacts of the variable $Q_{10}$ parameterization by PFT types on soil respiration and GPP will be discussed.

\section{b. Impacts of $Q_{10}$ variation on the carbon fluxes in CLM4}

Figure 5a shows the $R_{s}$ bias pattern simulated by the EXP run with respect to the reference soil respiration data from Hashimoto et al. Comparing with the bias in the CTL run (Fig. 3f), which shows the uniform pattern of underestimation in almost every region except central China, the EXP run produces positive and negative biases depending on regions, such as larger soil respiration in warm and wet regions in low latitudes and less respiration in cold and dry regions in high latitudes. The changes in $R_{s}$ simulation by EXP are given in Fig. 5b, in terms of global averaged values as well as area-averaged values over latitude belts. Overall, the modification to $Q_{10}$ tends to increase $R_{s}$ in most latitude belts, which is an improvement from CTL, even though the $R_{s}$ reference data from Hashimoto et al. (2015) are empirical and independent of the dynamical simulation by CLM4. The increase of $R_{S}$ in most latitude belts can be attributed to the increase of $Q_{10}$ in most of the vegetated regions (Fig. 2) from the standard value of 1.5 .

Figure 6a compares the GPP bias patterns in CTL and EXP, and Fig. 6b shows the actual GPP values averaged over six selected geographical regions (Eurasia, East Asia, Amazon, Europe, Africa, and North America). Among the biases, overestimation in the tropics and underestimation in Eurasia is evident in CTL (Fig. 6a). Although the spatial structure of bias seems to be quite similar, implying intrinsic model deficiencies other than $Q_{10}$, EXP shows an improvement by reducing biases such as overestimation in East Asia and China and underestimation in northern Eurasia in CTL (Fig. 6b). However, underestimation biases in the central part of North America and the Amazon are even larger in EXP. a) EXP - Hashimoto

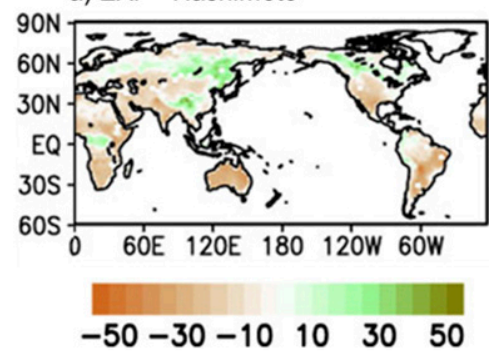

b) Regional average of $R_{s}$

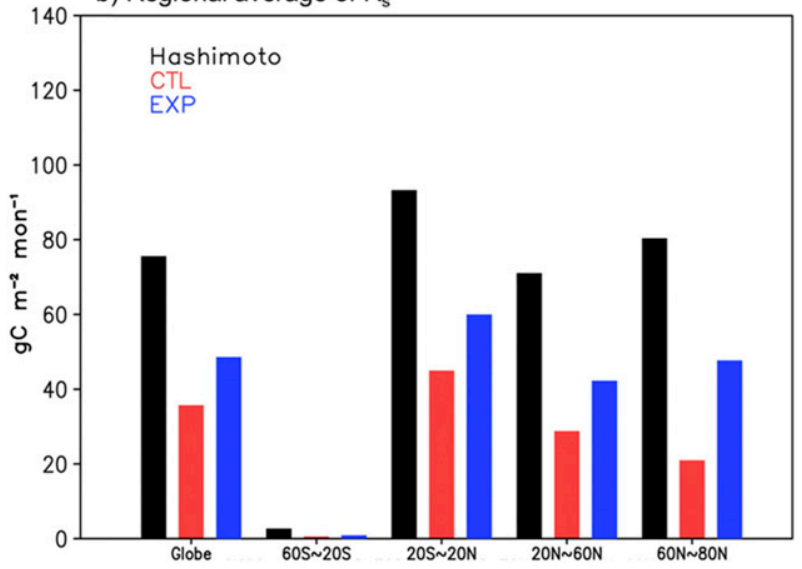

FIG. 5. (a) Spatial distribution of $R_{s}$ bias $\left(\mathrm{gC} \mathrm{m}^{-2} \mathrm{month}^{-1}\right)$ in EXP simulation from the reference data from Hashimoto et al. (b) Comparison of the regional average of $R_{s}$ between Hashimoto et al. data (black bars), CTL simulation (red bars), and EXP experiment (blue bars).

This change of spatial distribution of GPP is associated with sensitivity of $R_{s}$ to soil temperature (Table 4). Degradation of GPP simulation over Europe is driven by the temperate plant type where the temperature sensitivity of $R_{s}$ tends to decrease. On the other hand, the northern Eurasian and Chinese regions that have good improvement of GPP bias in EXP show an enhanced relationship between $R_{s}$ and temperature. This result indicates that the change of $R_{s}$ to soil temperature by $Q_{10}$ variation affects not only the change in respiration but also the carbon production (GPP) flux.

The improvement in the GPP simulation by the $Q_{10}$ parameterization is illustrated better in Fig. 6c, which compares the global and zonal averages of GPP. In the global average, the overestimated bias is substantially reduced from $+9.11(\mathrm{CTL})$ to $+1.68(\mathrm{EXP}) \mathrm{gCm}^{-2}$ month $^{-1}$, where the global GPP climatology simulated by CTL and EXP is 111.24 and $103.81 \mathrm{gC} \mathrm{m}^{-2}$ month $^{-1}$, respectively. Relatively little landmass in the Southern Hemisphere $\left(60^{\circ}-20^{\circ} \mathrm{S}\right)$ leads to a smaller GPP values, with no significant signal of improvement from CTL to EXP. However, the overestimation bias in the tropics has been improved significantly $\left(20^{\circ} \mathrm{S}-20^{\circ} \mathrm{S}\right)$, as well as 
a) Spatial distribution of bias of GPP GPP (CTL-FLUXNET)

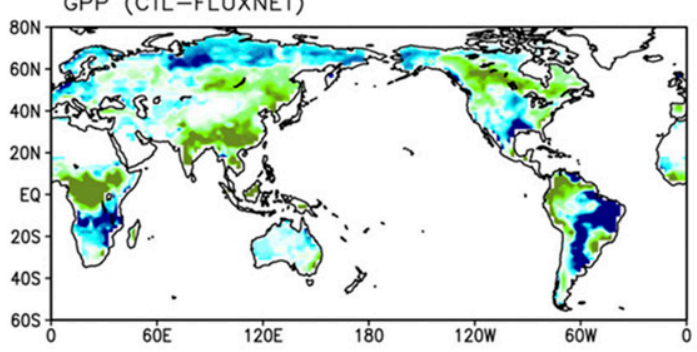

GPP (EXP-FLUXNET)

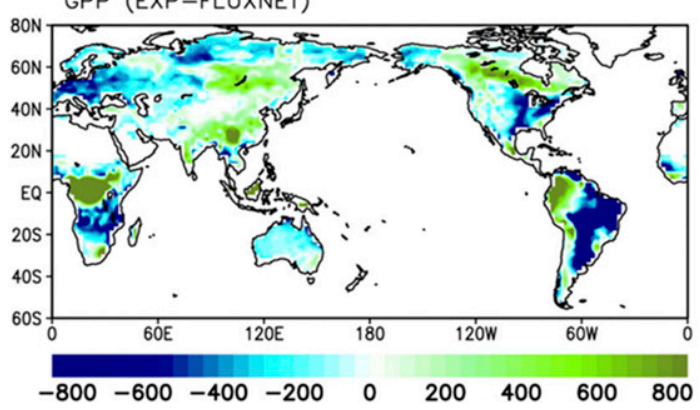

b) Regional averaged GPP

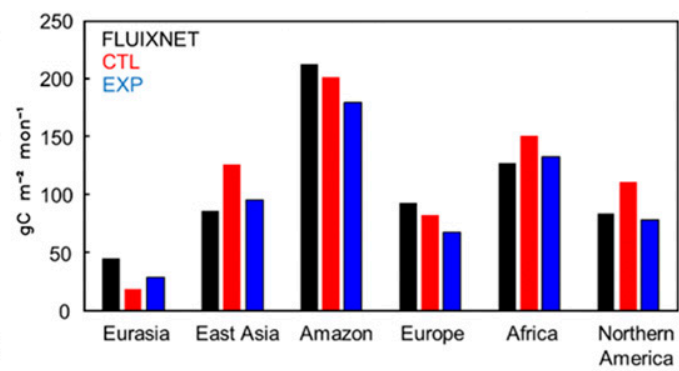

c) Zonal averaged GPP

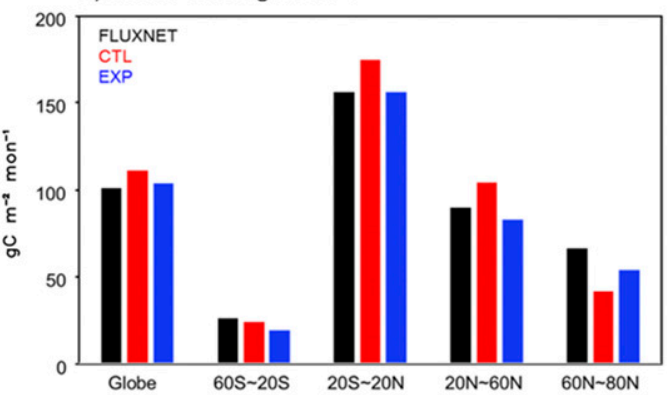

FIG. 6. (a) Spatial distributions of GPP bias $\left(\mathrm{gC} \mathrm{m}^{-2} \mathrm{yr}^{-}\right)$in the (top) CTL and (bottom) EXP runs comparing with FLUXNET for 23 years (1983-2005). (b) Regional averages of GPP from FLUXNET (black), CTL (red), and EXP (blue) in six selected regions, including Eurasia $\left(60^{\circ}-80^{\circ} \mathrm{N}, 60^{\circ} \mathrm{E}-180^{\circ}\right)$, East Asia $\left(5^{\circ}-60^{\circ} \mathrm{N}, 60^{\circ}-160^{\circ} \mathrm{E}\right)$, the Amazon $\left(35^{\circ} \mathrm{S}-10^{\circ} \mathrm{N}, 80^{\circ}-160^{\circ} \mathrm{W}\right)$, Europe $\left(40^{\circ}-70^{\circ} \mathrm{N}, 0^{\circ}-60^{\circ} \mathrm{E}\right)$, Africa $\left(20^{\circ} \mathrm{S}-20^{\circ} \mathrm{N}, 0^{\circ}-50^{\circ} \mathrm{E}\right)$, and North America $\left(30^{\circ}-60^{\circ} \mathrm{N}\right.$, $120^{\circ}-60^{\circ} \mathrm{W}$ ). (c) Global and zonal averages of GPP from FLUXNET (black), CTL (red), and EXP (blue).

in the midlatitudes $\left(20^{\circ}-60^{\circ} \mathrm{N}\right)$. In addition, simulated GPP over high latitudes $\left(60^{\circ}-80^{\circ} \mathrm{N}\right)$ is improved in EXP by increasing GPP values in the region.

The variable $Q_{10}$ in the parameterization of soil decomposition flux immediately affects the heterotrophic soil respiration as given by the model formulations in (2) and (3). Moreover, this modification changes the plant assimilation and GPP in the meantime in this carbonnitrogen coupled model. A faster (slower) carbon decomposition rate in the model tends to increase (decrease) nitrogen assimilation from soil to vegetation and plants, thereby increasing (decreasing) GPP. This aspect is illustrated well by comparing the turnover time of the soil carbon, which is defined as the ratio of soil carbon amount to the net primary production (NPP), between the CTL and EXP runs (Fig. 7). As shown in Fig. 7, the run with variable $Q_{10}(\mathrm{EXP})$ makes shorter turnover time in $\mathrm{NH}$ high latitudes and longer in the tropics compared with the CTL. It is suggested that enhanced temperature sensitivity of soil respiration in the high latitudes by variable $Q_{10}$ tends to decrease activation energy of SOM decomposition. This leads to a shorter turnover time, which is supported by previous observational studies (Craine et al. 2010; Lefèvre et al. 2014). The shorter turnover time in high latitudes suggests the enhancement of nitrogen assimilation to vegetation in EXP, thereby enhancing net primary production by plants.

Note that the simulated turnover time is about 10.2 years as a global average in CTL experiment. This is relatively shorter than the suggested values ranging from 18.5 to 32 years from the previous observational studies (e.g., Amundson 2001; Raich and Schlesinger 1992), although the CLM4 model in our offline experiments tends to reproduce a realistic geographical distribution of turnover time such as relatively longer turnover time for the boreal vegetated surface in cold temperature and shorter time for tropical forest. Our model result is consistent well with that from Todd-Brown et al. (2013),

TABLE 4. The $r^{2}$ values between $\log R_{s}$ and soil temperature by PFTs in CTL and EXP.

\begin{tabular}{lccccccc}
\hline \hline & Temperate & Boreal & Tropical & Shrub & Boreal shrub & Grass & Crop \\
\hline CTL & 0.42 & 0.12 & 0.34 & 0.06 & 0.14 & 0.38 & 0.27 \\
EXP & 0.36 & 0.27 & 0.31 & 0.05 & 0.31 & 0.28 & 0.37 \\
\hline
\end{tabular}


a) $\mathrm{CTL}$

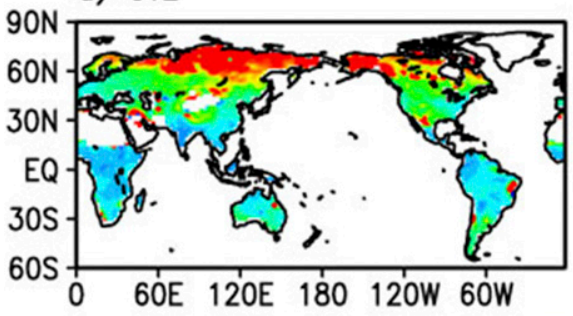

b) EXP

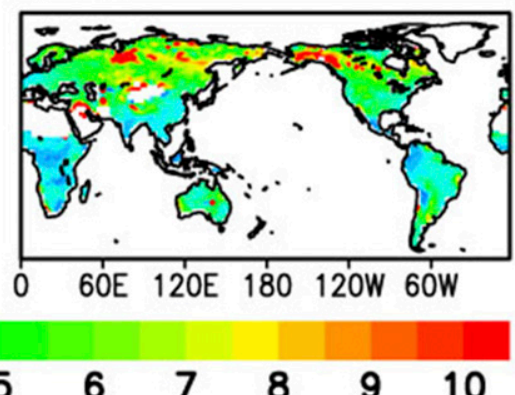

c) EXP-CTL

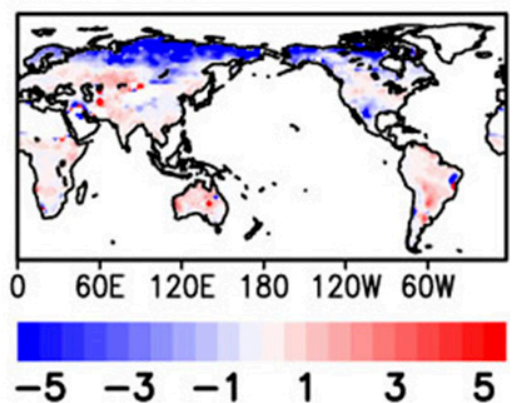

FIG. 7. Spatial distribution of turnover time (years) of soil carbon in (a) CTL and (b) EXP. (c) The difference between EXP and CTL simulation. The turnover time is defined as the ratio of the soil carbon amount to the net primary production (NPP).

who estimated the turnover time for 11 CMIP5 ESMs. Among the models, the CCSM4 model coupled with the CLM4 land model exhibited the lowest turnover time of about 10 years [See Fig. 2 in Todd-Brown et al. (2013)]. They attributed this model deficiency to a significant underestimation of soil carbon in the model.

Figure 8 compares the distribution of litter carbon from the two offline simulations. Although the two patterns look similar, EXP shows more accumulation of litter carbon in Eurasia. This result is somewhat consistent with the results from the Lund-Potsdam-Jena (LPJ) Dynamic Global Vegetation Model (DGVM) with the modified soil decomposition rate depending on the vegetation type (Gerten et al. 2004; Sitch et al. 2003). In Brovkin et al. (2012), the model experiment with PFT-dependent decomposition rate simulated larger litter stock carbon over NH high latitudes. In spite of differences in model formulations, the consistent result across the models suggests that the variation of decomposition rate by PFT can modify the spatial distribution of litter carbon and hence affect the entire decomposition cascade structure in the subsurface layers.
Nitrogen fluxes in the subsurface have also changed by the $Q_{10}$ parameterization through carbon-nitrogen coupling in this model. Figure 9 compares the total nitrogen assimilation flux from soil to plants between CTL and EXP, which is normalized by the global mean value and averaged over each latitude belt. The result clearly shows that reduced (increased) nitrogen assimilation over tropics (over NH high latitudes) corresponds to reduced (increased) GPP in the region by EXP (Fig. 6c).

The impacts of the spatiotemporal change of $Q_{10}$ for GPP simulation are also investigated in Fig. 10, which indicates the partial correlation between two environmental variables (soil temperature and moisture) and GPP. As shown in the reference data (Figs. 10a,d), the interannual variation in GPP over NH high latitudes is mainly correlated with soil temperature. The regions of strong seasonal variation of surface temperature such as in Siberia, Europe, and Alaska show more dominant impact on the vegetation growth, which can also contribute to the interannual variation of GPP significantly. In contrast, GPP over subtropics, tropics, and Australia is controlled more by soil moisture. Within $30^{\circ} \mathrm{S}-30^{\circ} \mathrm{N}$, the water availability limitation is more critical at the presence of weak seasonal temperature variation. The a) CTL

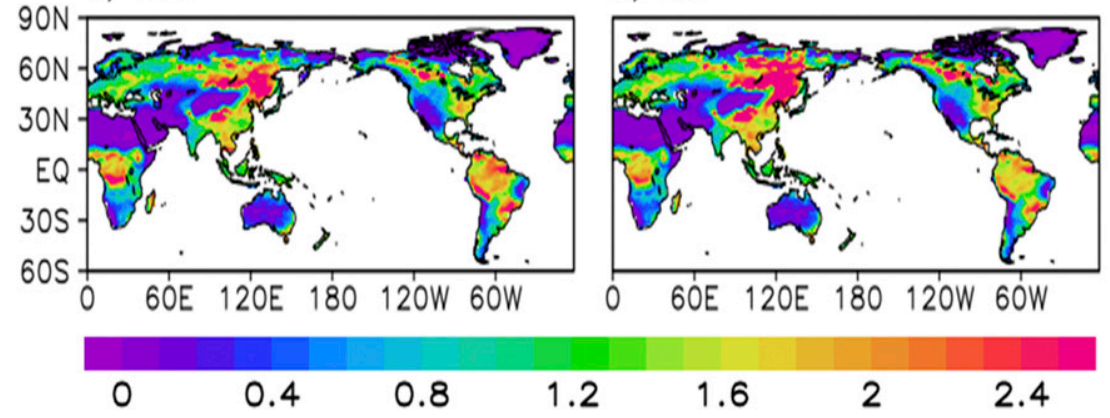

c) EXP - CTL

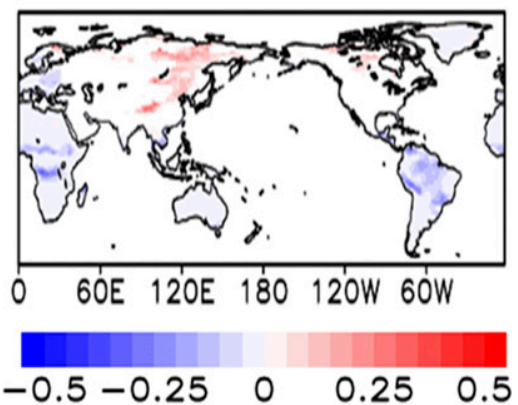

FIG. 8. Spatial distribution of litter carbon $\left(\mathrm{kg} \mathrm{C}^{-1} \mathrm{~m}^{-2}\right)$ in (a) CTL, (b) EXP, and (c) EXP minus CTL. 


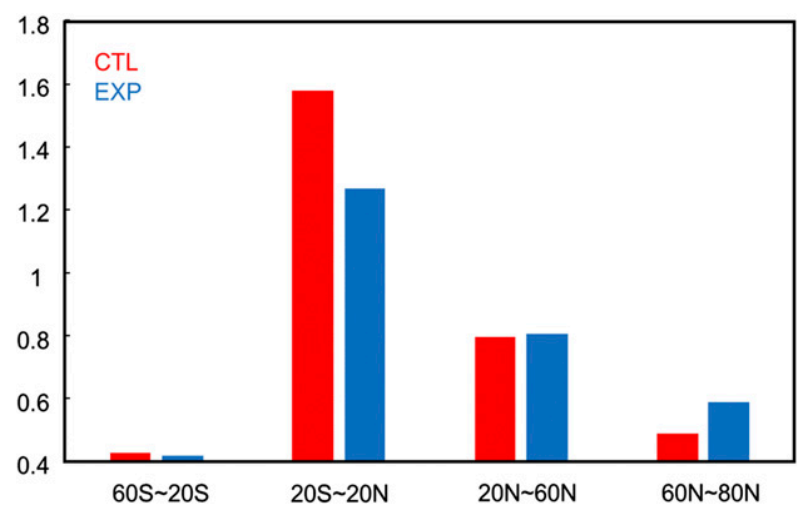

FIG. 9. Comparison of nitrogen assimilation from soil to plant simulated by CTL (red) and EXP (blue). Because of the large difference in the absolute amount, the values are normalized by the global mean values and then averaged over each latitude belts.

seasonal variation of precipitation is a major factor due to the global monsoon systems, which impacts significantly on the vegetation growth and GPP. Overall, the sensitivity shows a clear regional dependence, which is also confirmed by previous studies (e.g., Piao et al. 2009; Nemani et al. 2003). It is also noted that Amazonia is an exception with weak sensitivity both to temperature and to moisture, suggesting an important role of radiation (Piao et al. 2009; Nemani et al. 2003). CTL tends to reproduce the positive correlation between soil temperature and GPP in NH high latitudes, although the amplitude is relatively weaker than the reference data. On the other hand, CTL shows almost no significant correlation between soil moisture and GPP. These biases are also responsible for weaker correlation between NPP and precipitation over tropical land in the simulation of CESM-BGC coupled with CLM4 (Kim et al. 2016). Interestingly, the relationship between two climatic constraints and GPP is improved by the modified $Q_{10}$ parameterization in EXP. The run shows more enhanced relationship between soil temperature and GPP in NH high latitudes, as well as significant positive correlation between soil moisture and GPP over the subtropics and the tropics (Figs. 10c,f). It suggests that changeable $Q_{10}$ with time and space improves the impacts of soil temperature and moisture on GPP in CLM4. The modification to the soil process parameterization can affect the rest of the terrestrial carbon cycle by changing the carbon and nitrogen pools in the soil system needed for plant nitrogen assimilation.

For detailed investigation of the impact of the $Q_{10}$ parameterization, this study further investigates the changes in the simulated terrestrial carbon cycle of each vegetation type. Figure 11 compares the reference data and the simulations using two offline runs for GPP, $R_{a}$ by plants, and $R_{S}$ depending on the primary vegetation type. For the comparisons of GPP and $R_{a}$, satellitebased MODIS data were used as the data separated GPP and $R_{a}$ over vegetation areas. In the MODIS data, the terrestrial carbon cycle is largely contributed to by vegetation response in tropical and temperate tree regions. Vegetation types with a short canopy height and trees with deciduous leaves contribute less in terms of absolute amount of carbon fluxes, although their relative changes are not trivial. Both CTL and EXP runs capture these differences appeared in MODIS in the magnitude of carbon fluxes realistically. Regarding the simulation of GPP, EXP tends to reduce the biases, particularly in temperate, tropical, and crop zones. EXP also improves the simulation of $R_{a}$ in those regions. The improvement is most evident in $R_{s}$, where the simulated values are close to the observed values in most vegetation types. The amount of $R_{s}$ by EXP has been increased in every type of vegetation from CTL, reaching values closer to the reference observation data. According to this result, although the absolute magnitude of $R_{s}$ is much smaller compared with that of GPP and $R_{a}$, the modification of $R_{s}$ by the $Q_{10}$ parameterization affects the entire terrestrial carbon cycle and improves their simulations.

\section{Summary and concluding remarks}

Soil respiration is a crucial process in maintaining terrestrial carbon cycles. Although its sensitivity to the physical environmental conditions such as soil temperature and moisture depends on the type of vegetation, as supported by observational data, most contemporary ESMs do not consider this dependence. These models thereby underestimate the effects of and feedbacks from soil respiration on terrestrial carbon cycles. Using the CLM4 land surface model with the interactive C-N cycle, this study developed a new parameterization method to consider the spatiotemporal variation of $Q_{10}$ that represents the sensitivity of soil respiration to the temperature change for each different vegetation type. This sensitivity has been treated as constant with a uniform value regardless of plant type in the original CLM4 model.

This study first examined the biases in GPP and $R_{S}$ in the offline CLM4 simulation, which tended to reproduce most of the systematic biases appearing in the fully interactive Earth system model simulation of CESM-BGC that coupled with the identical CLM4 land surface model. Much resemblance in the terrestrial carbon-flux bias patterns suggests that the deficiency in the dynamic 
a) OBS

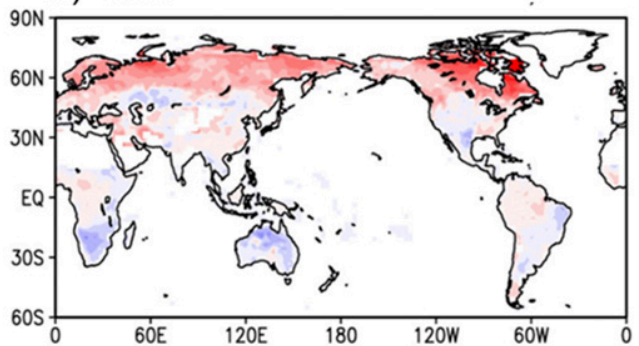

b) CTL

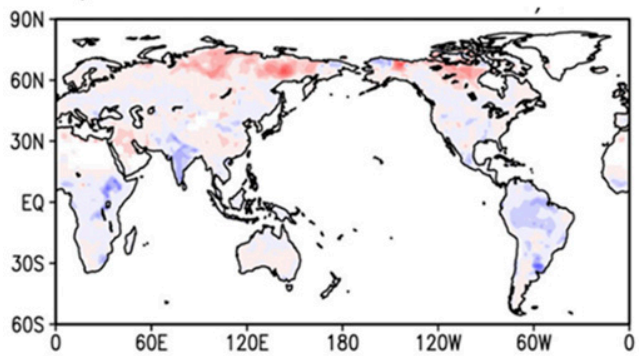

c) EXP
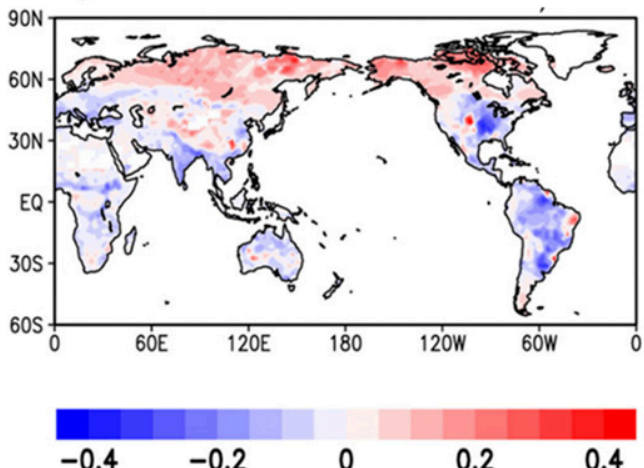

d) OBS

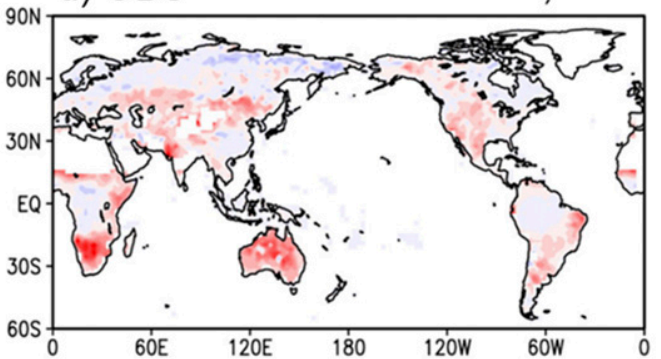

e) CTL

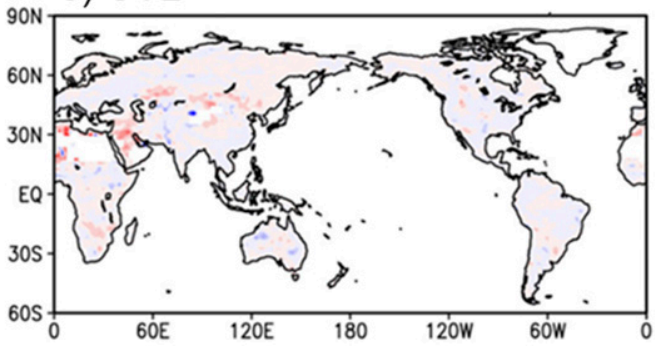

f) EXP
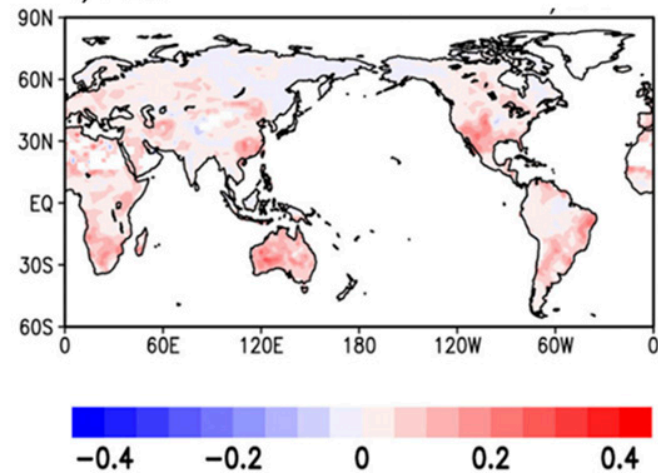

FIG. 10. Spatial distribution of partial correlation between (a)-(c) GPP and soil temperature and (d)-(f) GPP and soil moisture in (a),(d) observations, (b),(e) CTL, and (c),(f) EXP for 30 years.

vegetation model is overwhelming the systematic errors in the model.

The new parameterization changes the simulation of soil respiration and the rest of terrestrial carbon fluxes significantly by enhancing the feedback to the plant production process. The new parameterization calculates $Q_{10}$ at every time interval for each location, and this statedependent prescription induces the overall increase of soil respiration in most locations and most vegetation types, improving spatially uniform negative bias in the original CLM4 simulation with constant $Q_{10}$ value.

The simulated sensitivity of soil respiration to soil temperature and moisture by the new method showed more realistic features, particularly in the temperate and cold regions. This changed soil carbon fluxes at the subsurface and affected the simulation of GPP, where the simulation of spatial distribution of GPP has been improved particularly over NH high latitudes with short canopy heights and over the tropics and warm regions, including southern Asia and China. Furthermore, the new $Q_{10}$ parameterization mainly contributes to the substantial reduction of overestimated global mean GPP bias.

The improved GPP simulation over cold regions was mostly attributed to the increase in carbon decomposition in those regions. Because of the advancement of both respiration and primary production, the carbon balance between subsurface and surface ecosystems with soil organic matter and plants was also improved by the new $Q_{10}$ parameterization. The observed ratio of soil respiration to GPP was represented better in the new simulation, which clearly shows the dependence on the vegetation type. 

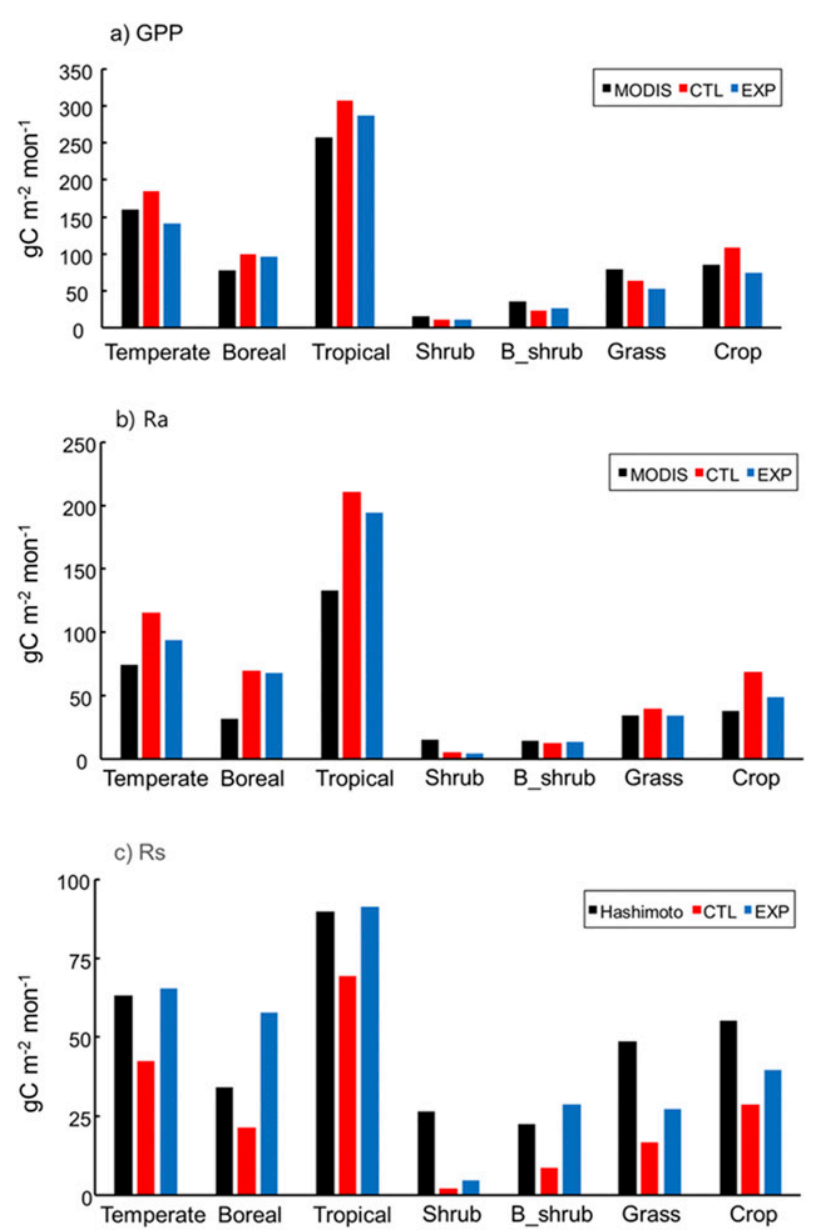

FIG. 11. Comparison of spatial average of (a) GPP, (b) $R_{a}$, and (c) $R_{s}$ in observation (black), CTL (red), and EXP (blue) by PFTs.

The major findings from this study suggest that the modification of subsurface terrestrial carbon cycle processes is important for improving the simulation of terrestrial carbon fluxes. The parameterization of the photosynthetic process is still a major term crucially related to primary production (Bonan and Levis 2010; Bonan et al. 2011). Previous studies have suggested that the improvement of canopy processes in the photosynthetic parameter in CLM4 was able to improve the simulation by reducing the overestimation of GPP in the tropics. Despite the improvement in the photosynthetic process in their models, respiration processes by plants and soil are still largely uncertain due to a lack of reliable observational data and comprehensive studies (Bonan and Levis 2010; Bonan et al. 2011). For this reason, this study approached the modification of the soil decomposition process, aiming to improve the terrestrial carbon cycle.

Still, large uncertainties lie in the formulation of the respiration process and its parameters. The major limitation in this study is in that, although the parameterization approach is physically based, actual implementation is not based on the use of real observation data for soil respiration, temperature, and moisture in the subsurface layers. As stated, this study used the $R_{s}$ data obtained from Hashimoto et al. (2015) as an alternative, because there are no real observation data available for the calibration of the multiple regression models for the vegetation typedependent parameterization of $Q_{10}$. This seems to be less ideal as the data were inferred from insufficient in situ observations and the empirical (statistical) relationship between $R_{s}$ and observed surface temperature and precipitation. Therefore, our $Q_{10}$ parameterization has much room for improvement, when more reliable observations are available.

This study suggested that the improved soil decomposition process induces a change in carbon-climate feedback intensity by changing soil respiration. In addition, the realistic description of $Q_{10}$ variation in a numerical model will reduce the uncertainty of the magnitude of carbon-climate feedback due to accurate atmospheric $\mathrm{CO}_{2}$ simulation in ESMs.

Acknowledgments. This study was supported by the Basic Science Research Program of the National Research Foundation of Korea (NRF), funded by the Ministry of Education, Science and Technology (NRF2012M1A2A2671851). The computing resource was supported by the Supercomputing Center of Korea Institute of Science and Technology Information including technical support (KSC-2015-C3-035).

\section{REFERENCES}

Amundson, R., 2001: The carbon budget in soil. Annu. Rev. Earth Planet. Sci., 29, 535-562, https://doi.org/10.1146/annurev.earth.29.1.535.

Anav, A., and Coauthors, 2013: Evaluating the land and ocean components of the global carbon cycle in the CMIP5 Earth system models. J. Climate, 26, 6801-6843, https://doi.org/ 10.1175/JCLI-D-12-00417.1.

Andren, O., and K. Paustian, 1987: Barley straw decomposition in the field: A comparison of models. Biology, 68, 1190-1200, https://doi.org/10.2307/1939203.

Arora, V. K., and Coauthors, 2009: The effect of terrestrial photosynthesis down regulation on the twentieth-century carbon budget simulated with the CCCma Earth system model. J. Climate, 22, 6066-6088, https://doi.org/10.1175/2009JCLI3037.1.

_ , and Coauthors, 2013: Carbon-concentration and carbonclimate feedbacks in CMIP5 Earth system models. J. Climate, 26, 5289-5314, https://doi.org/10.1175/JCLI-D-12-00494.1.

Beer, C., and Coauthors, 2010: Terrestrial gross carbon dioxide uptake: Global distribution and covariation with climate. Science, 329, 834-838, https://doi.org/10.1126/science.1184984.

Belay-Tedla, A., X. H. Zhou, B. Su, S. Q. Wan, and Y. Q. Luo, 2009: Labile, recalcitrant, and microbial carbon and nitrogen pools of a tallgrass prairie soil in the US Great Plains subjected to experimental warming and clipping. Soil Biol. Biochem., 41, 110-116, https://doi.org/10.1016/j.soilbio.2008.10.003. 
Bonan, G. B., 2008: Forests and climate change: Forcings, feedbacks, and the climate benefits of forests. Science, 320, 1444-1449, https://doi.org/10.1126/science.1155121.

— , and S. Levis, 2010: Quantifying carbon-nitrogen feedbacks in the Community Land Model (CLM4). Geophys. Res. Lett., 37, L07401, https://doi.org/10.1029/2010GL042430.

- , P. J. Lawrence, K. W. Oleson, S. Levis, M. Jung, M. Reichstein, D. M. Lawrence, and S. C. Swenson, 2011: Improving canopy processes in the Community Land Model version 4 (CLM4) using global flux fields empirically inferred from FLUXNET data. J. Geophys. Res., 116, G02014, https:// doi.org/10.1029/2010JG001593.

Bond-Lamberty, B., and A. Thomson, 2010: Temperature-associated increases in the global soil respiration record. Nature, $\mathbf{4 6 4}$, 579-582, https://doi.org/10.1038/nature08930.

Brovkin, V., P. M. van Bodegom, T. Kleinen, C. Wirth, W. K. Cornwell, J. H. Cornelissen, and J. Kattge, 2012: Plant-driven variation in decomposition rates improves projections of global litter stock distribution. Biogeosciences, 9, 565-576, https://doi.org/10.5194/bg-9-565-2012.

Collatz, G. J., M. Ribas-Carbo, and J. A. Berry, 1992: Coupled photosynthesis-stomatal conductance model for leaves of $\mathrm{C} 4$ plants. Funct. Plant Biol., 19, 519-538, https://doi.org/10.1071/ PP9920519.

Cox, P. M., R. A. Betts, C. D. Jones, S. A. Spall, and I. J. Totterdell, 2000: Acceleration of global warming due to carbon-cycle feedbacks in a coupled climate model. Nature, 408, 184-187, https://doi.org/10.1038/35041539.

Craine, J. M., N. Fierer, and K. K. McLauchlan, 2010: Widespread coupling between the rate and temperature sensitivity of organic matter decay. Nat. Geosci., 3, 854-857, https://doi.org/ 10.1038/ngeo1009.

Davidson, E. A., E. Belk, and R. D. Boone, 1998: Soil water content and temperature as independent or confounded factors controlling soil respiration in a temperate mixed hardwood forest. Global Change Biol., 4, 217-227, https://doi.org/ 10.1046/j.1365-2486.1998.00128.x.

Dirmeyer, P. A., 2006: The hydrologic feedback pathway for landclimate coupling. J. Hydrometeor., 7, 857-867, https://doi.org/ 10.1175/JHM526.1.

Dufresne J. L., P. Friedlingstein, M. Berthelot, L. Bopp, P. Ciais, L. Fairhead, H. Le Treut, and P. Monfray, 2002: On the magnitude of positive feedback between future climate change and the carbon cycle. Geophys. Res. Lett., 29, 1405 , https://doi.org/10.1029/2001GL013777.

Dunne, J. P., and Coauthors, 2013: GFDL's ESM2 global coupled climate-carbon Earth system models. Part II: Carbon system formulation and baseline simulation characteristics. J. Climate, 26, 2247-2267, https://doi.org/10.1175/JCLI-D-12-00150.1.

Farquhar, G. D., S. von Caemmerer, and J. A. Berry, 1980: A biochemical model of photosynthetic $\mathrm{CO}_{2}$ assimilation in leaves of C3 species. Planta, 149, 78-90, https://doi.org/ 10.1007/BF00386231.

Foley, J. A., I. C. Prentice, N. Ramankutty, S. Levis, D. Pollard, S. Sitch, and A. Haxeltine, 1996: An integrated biosphere model of land surface processes, terrestrial carbon balance, and vegetation dynamics. Global Biogeochem. Cycles, 10, 603-628, https://doi.org/10.1029/96GB02692.

— S. Levis, and I. C. Prentice, 1998: Coupling dynamic models of climate and vegetation. Global Change Biol., 4, 561-579, https://doi.org/10.1046/j.1365-2486.1998.t01-1-00168.x.

Friedlingstein, P., J. L. Dufresne, P. M. Cox, and P. Rayner, 2003: How positive is the feedback between climate change and the carbon cycle? Tellus, 55B, 692-700, https://doi.org/10.1034/ j.1600-0889.2003.01461.x.

- and Coauthors, 2006: Climate-carbon cycle feedback analysis: Results from the C4MIP model intercomparison. J. Climate, 19, 3337-3353, https://doi.org/10.1175/JCLI3800.1.

—, M. Meinshausen, V. K. Arora, C. D. Jones, A. Anav, S. K. Liddicoat, and R. Knutti, 2014: Uncertainties in CMIP5 climate projections due to carbon cycle feedbacks. J. Climate, 27, 511-525, https://doi.org/10.1175/JCLI-D-12-00579.1.

Gerten, D., S. Schaphoff, U. Haberlandt, W. Lucht, and S. Sitch, 2004: Terrestrial vegetation and water balance-Hydrological evaluation of a dynamic global vegetation model. J. Hydrol., 286, 249-270, https://doi.org/10.1016/j.jhydrol.2003.09.029.

Gregory, J. M., C. D. Jones, P. Cadule, and P. Friedlingstein, 2009: Quantifying carbon cycle feedbacks. J. Climate, 22, 5232-5249, https://doi.org/10.1175/2009JCLI2949.1.

Hashimoto, S., N. Carvalhais, A. Ito, M. Migliavacca, K. Nishina, and M. Reichstein, 2015: Global spatiotemporal distribution of soil respiration modeled using a global database. Biogeosciences, 12, 4121-4132, https://doi.org/10.5194/bg-12-4121-2015.

Hoffman, F. M., and Coauthors, 2014: Causes and implications of persistent atmospheric carbon dioxide biases in Earth system models. J. Geophys. Res. Biogeosci., 119, 141-162, https://doi.org/ 10.1002/2013JG002381.

Huffman, G. J., R. F. Adler, M. M. Morrissey, D. T. Bolvin, S. Curtis, R. Joyce, B. McGavock, and J. Susskind, 2001: Global precipitation at one-degree daily resolution from multisatellite observations. J. Hydrometeor., 2, 36-50, https:// doi.org/10.1175/1525-7541(2001)002<0036:GPAODD>2.0. $\mathrm{CO} ; 2$.

- — - E. F. Stocker, D. T. Bolvin, and E. J. Nelkin, 2003: Analysis of TRMM 3-hourly multi-satellite precipitation estimates computed in both real and post-real time. 12th Conf. on Satellite Meteorology and Oceanography, Long Beach, CA, Amer. Meteor. Soc., P4.11, https://ams.confex. com/ams/annual2003/techprogram/paper_54906.htm.

Hui, D., and Y. Luo, 2004: Evaluation of soil $\mathrm{CO}_{2}$ production and transport in Duke Forest using a process-based modeling approach. Global Biogeochem. Cycles, 18, GB4029, https://oi.org/ 10.1029/2004GB002297.

Hursh, A., A. Ballantyne, L. Cooper, M. Maneta, J. Kimball, and J. Watts, 2017: The sensitivity of soil respiration to soil temperature, moisture, and carbon supply at the global scale. Global Change Biol., 23, 2090-2103, https://doi.org/10.1111/ gcb.13489.

Ilyina, T., K. D. Six, J. Segschneider, E. Maier-Reimer, H. Li, and I. Núñez-Riboni, 2013: Global ocean biogeochemistry model HAMOCC: Model architecture and performance as component of the MPI-Earth system model in different CMIP5 experimental realizations. J. Adv. Model. Earth Syst., 5, 287-315, https://doi.org/10.1029/2012MS000178.

Jones, P., and I. Harris, 2013: CRU TS3.21: Climatic Research Unit (CRU) time-series (TS) version 3.21 of high resolution gridded data of month-by-month variation in climate (January 1901-December 2012), https://doi.org/10.5285/D0E1585D3417-485F-87AE-4FCECF10A992.

Jung, M., K. Henkel, M. Herold, and G. Churkina, 2006: Exploiting synergies of global land cover products for carbon cycle modeling. Remote Sens. Environ., 101, 534-553, https://doi.org/ 10.1016/j.rse.2006.01.020.

, M. Reichstein, and A. Bondeau, 2009: Towards global empirical upscaling of FLUXNET eddy covariance observations: Validation of a model tree ensemble approach using a biosphere 
model. Biogeosciences, 6, 2001-2013, https://doi.org/10.5194/ bg-6-2001-2009.

Kalnay, E., and Coauthors, 1996: The NCEP/NCAR 40-Year Reanalysis Project. Bull. Amer. Meteor. Soc., 77, 437-472, https:// doi.org/10.1175/1520-0477(1996)077<0437:TNYRP>2.0.CO;2.

Karhu, K., and Coauthors, 2014: Temperature sensitivity of soil respiration rates enhanced by microbial community response. Nature, 513, 81-84, https://doi.org/10.1038/nature13604.

Kim, D., M.-I. Lee, S.-J. Jeong, J. Im, D. H. Cha, and S. Lee, 2017: Intercomparison of terrestrial carbon fluxes and carbon use efficiency simulated by CMIP5 Earth system models. Asia-Pac. J. Atmos. Sci, 54, 145-163, https://doi.org/10.1007/s13143-017-0066-8.

Kim, J. S., J.-S. Kug, J.-H. Yoon, and S.-J. Jeong, 2016: Increased atmospheric $\mathrm{CO}_{2}$ growth rate during El Niño driven by reduced terrestrial productivity in the CMIP5 ESMs. J. Climate, 29, 8783-8805, https://doi.org/10.1175/JCLI-D-14-00672.1.

Kirschbaum, M. U. F., 1995: The temperature dependence of soil organic matter decomposition, and the effect of global warming on soil organic C storage. Soil Biol. Biochem., 27, 753-760, https://doi.org/10.1016/0038-0717(94)00242-S.

Koizumi, H., M. Kontturi, S. Mariko, T. Nakadai, Y. Bekku, and T. Mela, 2010: Soil respiration in three soil types in agricultural ecosystems in Finland. Soil Plant Sci., 49, 65-74, https://doi.org/ 10.1080/09064719950135560.

Kutsch, W. L., M. Bahn, and A. Heinemeyer, 2009: Soil Carbon Dynamics: An Integrated Methodology. Cambridge University Press, 298 pp.

Lefèvre, R., and Coauthors, 2014: Higher temperature sensitivity for stable than for labile soil organic carbon-Evidence from incubations of long-term bare fallow soils. Global Change Biol., 20, 633-640, https://doi.org/10.1111/gcb.12402.

Le Quéré, C., and Coauthors, 2009: Trends in the sources and sinks of carbon dioxide. Nat. Geosci., 2, 831-836, https://doi.org/ 10.1038/ngeo689.

Liski, J., H. Ilvesniemi, A. Makel, and K. J. Westman, 1999: $\mathrm{CO}_{2}$ emissions from soil in response to climatic warming are overestimated: The decomposition of old soil organic matter is tolerant of temperature. Ambio, 28, 171-174.

Lloyd, J., and J. A. Taylor, 1994: On the temperature dependence of soil respiration. Funct. Ecol., 8, 315-323, https://doi.org/ $10.2307 / 2389824$.

Long, M. C., K. Lindsay, S. Peacock, J. K. Moore, and S. C. Doney, 2013: Twentieth-century oceanic carbon uptake and storage in CESM1(BGC). J. Climate, 26, 6775-6800, https://doi.org/ 10.1175/JCLI-D-12-00184.1.

Luo, Y., S. Wan, D. Hui, and L. L. Wallace, 2001: Acclimatization of soil respiration to warming in a tall grass prairie. Nature, 413, 622-625, https://doi.org/10.1038/35098065.

, and Coauthors, 2016: Toward more realistic projections of soil carbon dynamics by Earth system models. Global Biogeochem. Cycles, 30, 40-56, https://doi.org/10.1002/ 2015 GB005239.

Luyssaert, S., and Coauthors, 2007: The $\mathrm{CO}_{2}$-balance of boreal, temperate and tropical forest derived from a global database. Global Change Biol., 13, 2509-2537, https://doi.org/10.1111/ j.1365-2486.2007.01439.x.

Mahecha, M. D., and Coauthors, 2010: Global convergence in the temperature sensitivity of respiration at ecosystem level. Science, 329, 838-840, https://doi.org/10.1126/science.1189587.

Malhi, Y., D. D. Baldocchi, and P. G. Jarvis, 1999: The carbon balance of tropical, temperate and boreal forests. Plant Cell Environ., 22, 715-740, https://doi.org/10.1046/j.13653040.1999.00453.x.
Mitchell, T. D., T. R. Carter, P. D. Jones, M. Hulme, and M. New, 2004: A comprehensive set of high-resolution grids of monthly climate for Europe and the globe: The observed record (1901-2000) and 16 scenarios (2001-2100). Tyndall Centre for Climate Change Research Working Paper 55, 30 pp., http:// ipcc-data.org/docs/tyndall_working_papers_wp55.pdf.

Monteith, J., 1972: Solar radiation and productivity in tropical ecosystems. J. Appl. Ecol., 9, 747-766, https://doi.org/10.2307/ 2401901.

Nemani, R. R., C. D. Keeling, H. Hashimoto, W. M. Jolly, S. C. Piper, C. J. Tucker, R. B. Myneni, and S. W. Running, 2003: Climate-driven increases in global terrestrial net primary production from 1982 to 1999 . Science, 300, 1560-1563, https:// doi.org/10.1126/science.1082750.

Obata, A., 2007: Climate-carbon cycle model response to freshwater discharge into the North Atlantic. J. Climate, 20, 5962-5976, https://doi.org/10.1175/2007JCLI1808.1.

Oleson, K., and Coauthors, 2013: Technical description of version 4.5 of the Community Land Model (CLM). NCAR Tech. Note NCAR/TN-503+STR, 420 pp.

Piao, S., P. Ciais, P. Friedlingstein, N. Noblet-Ducoudré, P. Cadule, N. Viovy, and T. Wang, 2009: Spatiotemporal patterns of terrestrial carbon cycle during the 20th century. Global Biogeochem. Cycles, 23, GB4026, https://doi.org/10.1029/ 2008 GB003339.

Qi, Y., M. Xu, and J. Wu, 2002: Temperature sensitivity of soil respiration and its effects on ecosystem carbon budget: Nonlinearity begets surprises. Ecol. Modell., 153, 131-142, https:// doi.org/10.1016/S0304-3800(01)00506-3.

Raich, J. W., and W. Schlesinger, 1992: The global carbon dioxide flux in soil respiration and its relationship to vegetation and climate. Tellus, 44B, 81-99, https://doi.org/10.3402/tellusb. v44i2.15428.

- C. S. Potter, and D. Bhagawati, 2002: Interannual variability in global soil respiration, 1980-1994. Global Change Biol., 8, 800-812, https://doi.org/10.1046/j.1365-2486.2002.00511.x.

Regnier, P., and Coauthors, 2013: Anthropogenic perturbation of the carbon fluxes from land to ocean. Nat. Geosci., 6, 597-607, https://doi.org/10.1038/ngeo1830.

Reichstein, M., J. D. Tenhunen, O. Roupsard, J.-M. Ourcival, S. Rambal, S. Dore, and R. Valentini, 2002: Ecosystem respiration in two Mediterranean evergreen Holm Oak forests: Drought effects and decomposition dynamics. Funct. Ecol., 16, 27-39, https://doi.org/10.1046/j.0269-8463.2001.00597.x.

Running, S. W., R. R. Nemani, F. A. Heinsch, M. Zhao, M. Reeves, and H. Hashimoto, 2004: A continuous satellite-derived measure of global terrestrial primary production. BioScience, 54, 547-560, https://doi.org/10.1641/0006-3568(2004)054[0547: ACSMOG]2.0.CO;2.

Ryan, M. G., 1991: Effects of climate change on plant respiration. Ecol. Appl., 1, 157-167, https://doi.org/10.2307/1941808.

Schaphoff, S., and Coauthors, 2018: LPJmL4-A dynamic global vegetation model with managed land-Part 1: Model description. Geosci. Model Dev., 11, 1343-1375, https://doi.org/ 10.5194/gmd-11-1343-2018.

Sellers, P. J., Y. Mintz, Y. C. Sud, and A. Dalcher, 1986: A simple biosphere model $(\mathrm{SiB})$ for use within general circulation models. J. Atmos. Sci., 43, 505-531, https://doi.org/10.1175/ 1520-0469(1986)043<0505:ASBMFU>2.0.CO;2.

Shao, P., X. Zeng, K. Sakaguchi, R. K. Monson, and X. Zeng, 2013: Terrestrial carbon cycle: Climate relations in eight CMIP5 Earth system models. J. Climate, 26, 8744-8764, https:// doi.org/10.1175/JCLI-D-12-00831.1. 
Sheffield, J., G. Goteti, and E. F. Wood, 2006: Development of a 50-year high-resolution global dataset of meteorological forcings for land surface modeling. J. Climate, 19, 3088-3111, https://doi.org/10.1175/JCLI3790.1.

Sitch, S., and Coauthors, 2003: Evaluation of ecosystem dynamics, plant geography and terrestrial carbon cycling in the LPJ dynamic global vegetation model. Global Change Biol., 9, 161-185, https://doi.org/10.1046/j.1365-2486.2003.00569.x.

Stackhouse, P. W., S. K. Gupta, S. J. Cox, M. J. Colleen, T. Zhang, and M. Chiacchio, 2004: 12-year surface radiation budget data set. GEWEX News, No. 14 (4), International GEWEX Project Office, Silver Spring, MD, 10-12.

Suseela, V., R. T. Conant, M. D. Wallenstein, and J. S. Dukes, 2012: Effects of soil moisture on the temperature sensitivity of heterotrophic respiration vary seasonally in an old-field climate change experiment. Global Change Biol., 18, 336-348, https://doi.org/10.1111/j.1365-2486.2011.02516.x.

Tang, J., and D. D. Baldocchi, 2005: Spatial-temporal variation in soil respiration in an oak-grass savanna ecosystem in California and its partitioning into autotrophic and heterotrophic components. Biogeochem., 73, 183-207, https://doi.org/10.1007/s10533004-5889-6.

Taylor, B. R., D. Parkinson, and W. F. J. Parsons, 1989: Nitrogen and lignin content as predictors of litter decay rates: A microcosm test. Ecology, 70, 97-104, https://doi.org/10.2307/ 1938416.

Thornton, P. E., and N. A. Rosenbloom, 2005: Ecosystem model spin-up: Estimating steady state conditions in a coupled terrestrial carbon and nitrogen cycle model. Ecol. Modell., 189, 25-48, https://doi.org/10.1016/j.ecolmodel.2005.04.008.

_- and Coauthors, 2009: Carbon-nitrogen interactions regulate climate-carbon cycle feedbacks: Results from an atmosphereocean general circulation model. Biogeosciences, 6, 2099-2120, https://doi.org/10.5194/bg-6-2099-2009.

Tjiputra, J. F., C. Roelandt, M. Bentsen, D. M. Lawrence, T. Lorentzen, J. Schwinger, Ø. Seland, and C. Heinze, 2013: Evaluation of the carbon cycle components in the Norwegian Earth System Model (NorESM). Geosci. Model Dev., 6, 301-325, https://doi.org/10.5194/gmd-6-301-2013.

Todd-Brown, K. E. O., J. T. Randerson, W. M. Post, F. M. Hoffman, C. Tarnocai, E. A. G. Schuur, and S. D. Allison,
2013: Causes of variation in soil carbon simulations from CMIP5 Earth system models and comparison with observations. Biogeosciences, 10, 1717-1736, https://doi.org/10.5194/ bg-10-1717-2013.

Trumbore, S., 2006: Carbon respired by terrestrial ecosystemsRecent progress and challenges. Global Change Biol., 12, 141-153, https://doi.org/10.1111/j.1365-2486.2006.01067.x.

van't Hoff, J. H., 1898: Part I: Chemical dynamics. Lectures on Theoretical and Physical Chemistry. Edward Arnold, 224-229.

Wan, S., and Y. Luo, 2003: Substrate regulation of soil respiration in a tallgrass prairie: Results of a clipping and shading experiment. Global Biogeochem. Cycles, 17, 1054, https://doi.org/ 10.1029/2002GB001971.

Wang, Y. P., R. M. Law, and B. Pak, 2010: A global model of carbon, nitrogen and phosphorus cycles for the terrestrial biosphere. Biogeosciences, 7, 2261-2282, https://doi.org/10.5194/ bg-7-2261-2010.

Watanabe, S., and Coauthors, 2011: MIROC-ESM 2010: Model description and basic results of CMIP5-20c3m experiments. Geosci. Model Dev., 4, 845-872, https://doi.org/10.5194/ gmd-4-845-2011.

Wu, T., and Coauthors, 2013: Global carbon budgets simulated by the Beijing Climate Center Climate System Model for the last century. J. Geophys. Res. Atmos., 118, 4326-4347, https://doi.org/ 10.1002/jgrd.50320.

$\mathrm{Xu}$, M., and Y. Qi, 2001: Soil-surface $\mathrm{CO}_{2}$ efflux and its spatial and temporal variations in a young ponderosa pine plantation in northern California. Global Change Biol., 7, 667-677, https:// doi.org/10.1046/j.1354-1013.2001.00435.x.

Yukimoto, S., and Coauthors, 2011: Meteorological Research Institute-Earth System Model version 1 (MRI-ESM1): Model description. Meteorological Research Institute Tech. Rep. 64, 88 pp., https://doi.org/10.11483/mritechrepo.64.

Zhao, M. S., F. A. Heinsch, R. R. Nemani, and S. W. Running, 2005: Improvements of the MODIS terrestrial gross and net primary production global data set. Remote Sens. Environ., 95, 164-176, https://doi.org/10.1016/j.rse.2004.12.011.

Zhou, T., P. Shi, D. Hui, and Y. Luo, 2009: Global pattern of temperature sensitivity of soil heterotrophic respiration $\left(\mathrm{Q}_{10}\right)$ and its implications for carbon-climate feedback. J. Geophys. Res., 114, G02016, https://doi.org/10.1029/2008JG000850. 